\title{
Effects of dynamic ultra-high pressure homogenization on the structure and functional properties of casein
}

\author{
Chunyan Wang ${ }^{1}$, Yaping Ma ${ }^{1}$, Benguo Liu ${ }^{1}$, Zhuangli Kang ${ }^{1}$, Sheng Geng ${ }^{1}$, Jianan Wang ${ }^{1}$, \\ Lipeng Wei ${ }^{1}$, Hanjun $\mathrm{Ma}^{1,2^{*}}$ \\ (1. School of Food Science, Henan Institute of Science and Technology, Xinxiang 453003, China; \\ 2. National R\&D Center for Pork Processing Technology, Xinxiang 453003, China)
}

\begin{abstract}
Dynamic ultra-high pressure homogenization (UHPH) is a novel high-pressure processing technique. In this study, the effects of dynamic UHPH on the structure and functional properties of casein were systematically investigated. It was found that the functional properties of casein changed with dynamic UHPH treatment, and the treatment at 150 MPa could significantly improve casein aqueous solubility, foaming and emulsifying properties. These functional improvements could be attributed to its structural changes, since the dynamic UHPH treatment could change the secondary structure, promote the interchange reaction between the disulfide bond and the sulfhydryl group, and increase the surface hydrophobicity. The obtained results could broaden the application of casein and provide ideas for the non-thermal processing of proteins.

Keywords: casein, dynamic ultra-high pressure homogenization, functional properties, secondary structure, hydrophobicity, non-thermal processing
\end{abstract}

DOI: $10.25165 /$ j.ijabe.20191201.3015

Citation: Wang C Y, Ma Y P, Liu B G, Kang Z L, Geng S, Wang J N, et al. Effects of dynamic ultra-high pressure homogenization on the structure and functional properties of casein. Int J Agric \& Biol Eng, 2019; 12(1): 229-234.

\section{Introduction}

Casein accounts for $80 \%$ of the total protein in milk ${ }^{[1]}$. It can be precipitated from milk at $20^{\circ} \mathrm{C}$ by adjusting the $\mathrm{pH}$ to $4.6^{[2]}$. Casein is not only a good complete protein, but also a source of more than 100 types of active peptides ${ }^{[3]}$. Studies have shown that the bioactive peptides isolated from casein have many biological activities, such as antibacterial activity, regulation of the activities of the gastrointestinal tract, blood pressure-, blood sugar-, and blood lipid-lowering effects, free radical scavenging activity, anti-cancer activity, and immunity enhancing effect ${ }^{[4,5]}$. However, casein is insoluble in water and organic solvents, which limits the full use of its biological activities. Therefore, it is necessary to improve the utilization rate of casein. Wang et al. ${ }^{[6]}$ applied the heat treatment to improve the properties of casein in yak milk; Huang et al. ${ }^{[7]}$ studied the impact of ultrasound on the gelling properties of casein; Rahimi et al. ${ }^{[8]}$ conducted enzymatic hydrolysis of casein in camel milk using protease $\mathrm{K}$ to obtain the bioactive peptides that scavenged free radicals. In recent years, researchers have used dynamic ultra-high pressure homogenization (UHPH) to improve the structural and functional properties of some proteins. Dynamic UHPH is a novel and special physical modification technique ${ }^{[9]}$, by which the structures

Received date: 2016-11-19 Accepted date: 2019-01-06

Biographies: Chunyan Wang, Master, research interest: meat science, Email: m18236140794@163.com; Yaping Ma, Master, research interest: meat science, Email: hnxxmyp@163.com; Benguo Liu, PhD, Professor, research interest: food chemistry, Email: zzgclbg@126.com; Zhuangli Kang, PhD, Associate Professor, research interest: meat science, Email: kzlnj1988@163.com; Sheng Geng, $\mathrm{PhD}$, research interest: food chemistry, Email: gengshenggs@126.com; Jianan Wang, Master, research interest: meat science, Email: xxjnwang@163.com; Lipeng Wei, Master, research interest: meat science, Email: wlp5911@163.com. *Corresponding author: Hanjun Ma, $\mathrm{PhD}$, Professor, research interest: meat science. School of Food Science, Henan Institute of Science and Technology, Xinxiang 453003, China. Tel: +86-373-3040979, Email: xxhjma@126.com. of biomacromolecules, i.e. proteins and starches, will change due to the strong shearing force, high-speed impact, high-frequency oscillation, instantaneous pressure release, and other dynamic actions applied to the materials in the reaction chamber, resulting in certain changes in the functional properties of the materials ${ }^{[10-12]}$. Dynamic UHPH has been used to improve the functional properties of peanut $\operatorname{protein}^{[13]}$, soy $\operatorname{protein}^{[14]}$, whey $\operatorname{protein}^{[15]}$, and others. However, few studies have been reported on the application of dynamic UHPH to improve the functional properties of casein. In this study, this technique was used to treat casein, study the changes of casein structure and functional properties to broaden the application of casein and provide ideas for the pretreatment of the proteolysis.

\section{Materials and methods}

\subsection{Materials}

Casein, glycine, Tris, 5,5'-dithiobis(2-nitrobenzoic acid) (DTNB), trichloroacetic acid (TCA), 1-anilino-8-naphthalenesulfonic acid (ANS), and anhydrous ethanol were purchased from Tianjin Kemiou Chemical Reagent Co., Ltd. (Tianjin, China), and $\beta$-mercaptoethanol was purchased from Synthese (Shanghai, China).

\subsection{Dynamic UHPH treatment of casein solution}

The casein solution at the concentration of $10 \mathrm{mg} / \mathrm{mL}$ was prepared with the phosphate buffer solution ( $\mathrm{pH}$ 6.25) and incubated in water bath at $30^{\circ} \mathrm{C}$ for $10 \mathrm{~min}$, and then homogenized with a sterile homogenizer (Xinzhi Biotech Co., Ltd., Ningbo, China) for $12 \mathrm{~min}$ to disperse the casein. After homogenization, the casein solution was treated by a FPG12805 ultra-high pressure homogenizer (SFP Inc., UK) for 1 cycle at the designed pressure (25 MPa, $50 \mathrm{MPa}, 100 \mathrm{MPa}, 150 \mathrm{MPa}, 200 \mathrm{MPa}$, and $250 \mathrm{MPa}$ ) with the feeding volume of $10 \mathrm{~mL}$. The temperature of the obtained solution was immediately measured by an infrared thermometer. 


\subsection{Determination of the particle size of casein}

The effect of UHPH on the particle size of casein was evaluated by using the laser light scattering method ${ }^{[16]}$. The obtained casein solution in 2.2 was immediately injected into a BT-9300H laser particle size analyzer (Bettersize, Dandong, China) equipped with a BT-601 Circulating disperser. The particle size of casein was measured and recorded by using the software Bettersize 7.21.

\subsection{Measurement of the aqueous solubility}

The aqueous solubility of casein was determined based on Kjeldahl method ${ }^{[17,18]}$. The casein solution obtained in 2.2 was centrifugated at $10000 \mathrm{r} / \mathrm{min}$ for $15 \mathrm{~min}$ in order to remove the insoluble protein. The casein content in supernatant was evaluated by using a FOSS 8400 automatic kieldahl apparatus (Hillerød, Denmark), and the solubility of casein was calculated according to the following formula:

$$
\text { Solubility }(\%)=\frac{\text { Protein content in the supernatant }}{\text { Total protein content }} \times 100 \%
$$

\subsection{Determination of the foaming properties}

The foaming properties of casein were measured according to previous report ${ }^{[19]}$. The treated casein solution $(100 \mathrm{~mL})$ was dispersed at $9500 \mathrm{r} / \mathrm{min}$ for $2 \mathrm{~min}$ by a high-speed dispersion homogenizer. Both the volumes of the foam at $0 \mathrm{~min}\left(V_{0}\right)$ and at $30 \min \left(V_{30}\right)$ in the graduated cylinder were recorded, respectively. Then, the foaming capability and foaming stability were respectively obtained by using the following formulas:

$$
\begin{gathered}
\text { Foamability }(\%)=\frac{\left(V_{0}-100\right)}{100} \times 100 \% \\
\text { Foaming stability }(\%)=\frac{\left(V_{30}-100\right)}{\left(V_{0}-100\right)} \times 100 \%
\end{gathered}
$$

\subsection{Determination of the emulsifying properties}

$12 \mathrm{~mL}$ treated casein solution was mixed with $4 \mathrm{~mL}$ soybean oil, and the mixture was emulsified with a high-speed homogenizer at $13500 \mathrm{r} / \mathrm{min}$ for $2 \mathrm{~min}$. Then, $50 \mu \mathrm{L}$ of the emulsion was taken from the bottom of the beaker and mixed with $5 \mathrm{~mL}$ of $0.1 \mathrm{~g} / 100 \mathrm{~mL}$ sodium dodecyl sulfate (SDS) solution. The initial absorbance $\left(\mathrm{A}_{0}\right)$ was measured at $500 \mathrm{~nm}$, and the corresponding absorbance $\left(\mathrm{A}_{30}\right)$ was also recorded using the same method after the emulsion standing for $30 \mathrm{~min}$. The foamability (EA) and foaming stability (ES) were calculated according to the following formulas ${ }^{[20]}$ :

$$
\begin{gathered}
E A=2 T \frac{A_{0}}{c \times \varphi \times(1-\theta) \times 10^{5}} \\
E S=\frac{A_{0}}{A_{0}-A_{30}} \times 30
\end{gathered}
$$

where, $T=2.303 ; E A$ was emulsifying ability in $\mathrm{m}^{2} / \mathrm{g} ; E S$ was emulsifying stability in min; $\mathrm{c}$ was the casein concentration before the formation of emulsion in $\mathrm{g} / \mathrm{mL} ; \varphi$ was the optical path length (0.01); $\theta$ was the volume fraction of oil in the emulsion (0.25).

The particle size distribution of the casein emulsion was determined by a nano-ZS90 Malvern nanoparticle size analyzer (Malvern Instruments Ltd., Worcestershire, UK) with $\mathrm{He} / \mathrm{Ne}$ laser $(\lambda=633 \mathrm{~nm})$ and a scatter angle of $173^{\circ}$. The casein emulsion was added to a polystyrene cuvette (refractive index: 1.33). After held at $25^{\circ} \mathrm{C}$ for $3 \mathrm{~min}$, the average particle size of the emulsion was measured and recorded by Malvern Zetasizer software 7.11 .

\subsection{Determination of the content of the sulfhydryl group and the disulfide bond}

The contents of free sulfhydryl group $\left(\mathrm{SH}_{\mathrm{F}}\right)$ and the disulfide bond were analyzed according to previous report ${ }^{[21]}$. Briefly, $0.5 \mathrm{~mL}$ of the UHPH-treated casein solution was mixed with $2.5 \mathrm{~mL}$ of Tris-gly- $8 \mathrm{M}$ urea solution $(0.086 \mathrm{M}$ Tris, $0.09 \mathrm{M}$ glycine, $0.004 \mathrm{M}$ EDTA and $8 \mathrm{M}$ urea) and $0.02 \mathrm{~mL}$ of 5,5'-dithiobis-2nitrobenzoic acid solution (DTNB, $4 \mathrm{mg} / \mathrm{mL}$ ). The obtained mixture was incubated at $25^{\circ} \mathrm{C}$ for $30 \mathrm{~min}$, and its absorbance was measured at $412 \mathrm{~nm}\left(\mathrm{~A}_{412}\right)$. The mixture without casein solution was used as the blank control.

For the measurement of the total sulfhydryl group $\left(\mathrm{SH}_{\mathrm{T}}\right)$ content, $0.2 \mathrm{~mL}$ of the obtained casein solution in Section 2.2 was taken to mix with $1.0 \mathrm{~mL}$ of Tris-glycine-10 M urea solution (0.086 M Tris, $0.09 \mathrm{M}$ glycine, $0.004 \mathrm{M}$ EDTA and $10 \mathrm{M}$ urea) and $0.02 \mathrm{~mL}$ of $\beta$-mercaptoethanol, and incubated at $25^{\circ} \mathrm{C}$ for $1 \mathrm{~h}$. Subsequently, $10 \mathrm{~mL}$ of $12 \%$ TCA solution was added, and the solution was maintained for another $1 \mathrm{~h}$, followed by centrifugation at $3000 \mathrm{r} / \mathrm{min}$ for $10 \mathrm{~min}$. The precipitate was then rinsed with $12 \%$ of TCA solution, and followed by centrifugation at $3000 \mathrm{r} / \mathrm{min}$ for $10 \mathrm{~min}$. The procedure was repeated twice, and the precipitate was dissolved by adding $3 \mathrm{~mL}$ of Tris-gly- $8 \mathrm{M}$ urea and $0.03 \mathrm{~mL}$ of DTNB solution. Immediately, the mixture was mixed evenly to promote reaction at $25^{\circ} \mathrm{C}$ for $30 \mathrm{~min}$. The absorbance at $412 \mathrm{~nm}$ $\left(\mathrm{A}_{412}\right)$ was measured, and the absorbance of the blank was also determined by using the sample without casein solution. The content of the sulfhydryl group and the disulfide bond were calculated using the following formulas:

$$
\begin{aligned}
& \text { Sulfhydryl group content }(\mu \mathrm{mol} / \mathrm{g} \text { protein })=\frac{73.53 \mathrm{~A}_{412}}{\mathrm{C}} \\
& \text { Disulfide bond content }(\mu \mathrm{mol} / \mathrm{g} \text { protein })=\frac{\mathrm{SH}_{\mathrm{T}}-\mathrm{SH}_{\mathrm{F}}}{2}
\end{aligned}
$$

where, $\mathrm{A}_{412}$ was the absorbance at $\lambda=412 \mathrm{~nm}$; $\mathrm{C}$ was the casein concentration of the sample in $\mathrm{mg} / \mathrm{mL}$.

\subsection{Determination of surface hydrophobicity}

The surface hydrophobicity of the sample was measured using the ANS fluorescent probe method ${ }^{[22]} .4 \mathrm{~mL}$ of the treated casein solution at different concentrations $(0.005 \%-0.2 \%)$ were mixed with $20 \mu \mathrm{L}$ of $8.0 \mathrm{mM}$ ANS solution, and the fluorescence intensity (FI') of the mixture was rapidly measured on an Agilent Cary Eclipse fluorescence spectrophotometer (Santa Clara, CA, USA). The excitation and the emission wavelengths were set at $338 \mathrm{~nm}$ and $496 \mathrm{~nm}$, respectively. The control of fluorescence intensity, mixture without ANS, was also recorded as $\mathrm{FI}_{0}$. The FI value was obtained by the following equation:

$$
\mathrm{FI}=\mathrm{FI}^{\prime}-\mathrm{FI}_{0}
$$

A graph was made with the casein concentration as abscissa and FI as ordinate. The slope of the curve was the surface hydrophobicity index $\mathrm{H}_{0}$ of casein.

\subsection{Measurement of secondary structure}

The secondary structure of the sample was measured using a Chirascan circular dichroic spectrometer (Applied Photophysics Ltd. Surrey, UK) ${ }^{[23]}$. The phosphate buffer solution ( $\mathrm{pH}$ 6.25) was served as a blank control. A quartz cuvette with the path length of $1.0 \mathrm{~mm}$ was used. The sample was scanned from $190 \mathrm{~nm}$ to $250 \mathrm{~nm}$ at a scanning speed of $100 \mathrm{~nm} / \mathrm{min}$, resolution of $0.2 \mathrm{~nm}$, slit width of $1.0 \mathrm{~nm}$, sensitivity of $20 \mathrm{mdeg}$, and response time of $0.25 \mathrm{~s}$. The contents of secondary structure conformational units $(\alpha$-helix, $\beta$-sheet, $\beta$-turn and random coil) of casein were analyzed by the spectrometer software.

\subsection{Statistical analysis}

Each sample was measured in triplicate. The obtained results were expressed as mean \pm standard deviation. The statistics 
analysis was performed by using IBM SPSS 17.0 (Armonk, NY, USA) and Origin 8.0 (Northampton, MA, USA).

\section{Results and discussion}

\subsection{Effects of dynamic UHPH on the temperature of casein solution}

Dynamic UHPH treatment can increase the temperature of the material and the machine during the processing. It was reported that a large amount of heat could be generated when the material was forced to pass through the homogenization valve under high pressure produced by the pump ${ }^{[24]}$. As a result, the temperature of the solution was increased, and the increase magnitude of the temperature was closely related with the pressure. Figure 1 showed the effects of dynamic UHPH pressure on the temperature of casein solution. The temperature of the casein solution increased linearly with the increasing of pressure. But when the processing pressure exceeded $200 \mathrm{MPa}$, the temperature changed gently. During the process, the temperature of casein solution could be controlled to below $55^{\circ} \mathrm{C}$. Compared with the traditional heat treatment method, it is more mild, energy-saving and environmental friendly.

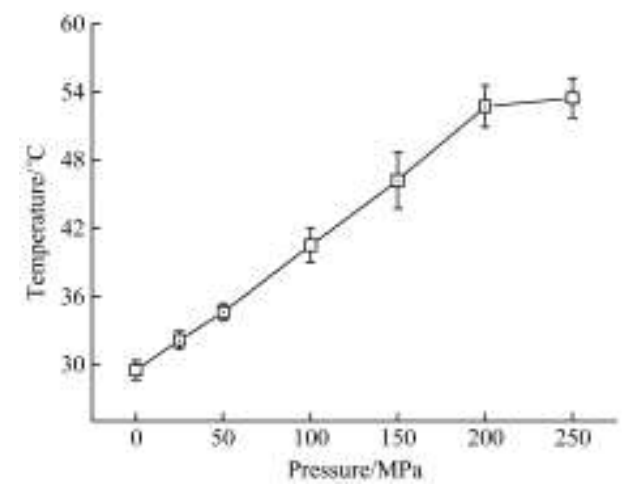

Figure 1 Effects of dynamic UHPH on the temperature of casein solution

\subsection{Effects of dynamic UHPH on the particle size of casein}

The effects of different dynamic UHPH treatment on the median particle size of casein were shown in Figure 2. With the increasing of pressure, the median particle size of the casein showed a gradual upward trend after the initial sharp decrease. The decrease in the median particle size of the treated casein was found because the casein was subjected to the strong shearing force, high-speed impact, high-frequency oscillation, instantaneous pressure release, and other dynamic actions in the reaction chamber, which dispersed the casein particles and destroyed the aggregates, thus reduced the median diameter of the casein particles. With the further increase of pressure, the casein particles were further broken down, the casein polymer was broken down into smaller aggregates, and the new surfaces were created. Because of the existence of thermodynamically unstable parts, the newly formed polymers were aggregated again. As shown in Figure 2, no significant differences were found in the median particle size among the casein samples treated in the pressure range of 50$250 \mathrm{MPa}$, indicating that the particle breakage and particle recombination reached a dynamic equilibrium when the pressure was between 50-250 MPa. In summary, the casein with a relatively small particle size could be obtained by dynamic UHPH treatment in the range of 50-250 MPa. It was also found that both casein samples treated at 150-300 MPa had the similar particle size distribution.

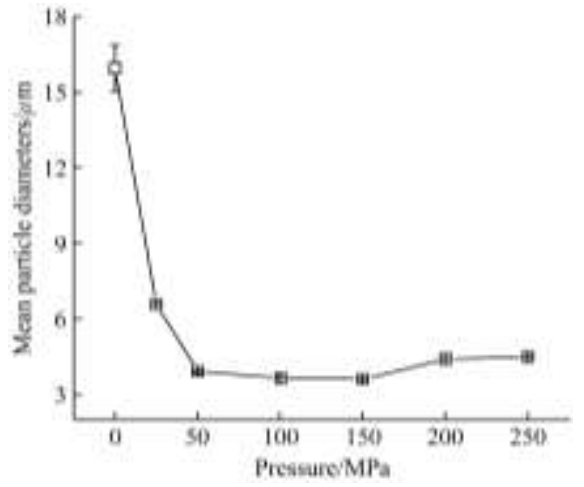

Figure 2 Effects of dynamic UHPH on the median particle size of casein

3.3 Effects of dynamic UHPH on the aqueous solubility of casein

The aqueous solubility of a protein generally refers to its water-solubility, which is the primary property of the functional properties of a protein and is the basis of other functions. A protein with a good solubility has good emulsifying ability, foamability, gelling properties, and other functional properties, and is also easier to be utilized in food processing applications ${ }^{[25]}$. The effects of dynamic UHPH on the aqueous solubility of casein were shown in Figure 3, which indicated that the solubility of casein increased firstly and then decreased with the increasing of pressure. This might because the dynamic UHPH treatment decreased the casein particle size, increased the contact area of casein with water, and resulted in an increased aqueous solubility. But according to previous report, higher pressure could expose more hydrophobic residues hidden in the interior of the protein, which could decrease the aqueous solubility of $\operatorname{casein}^{[26]}$.

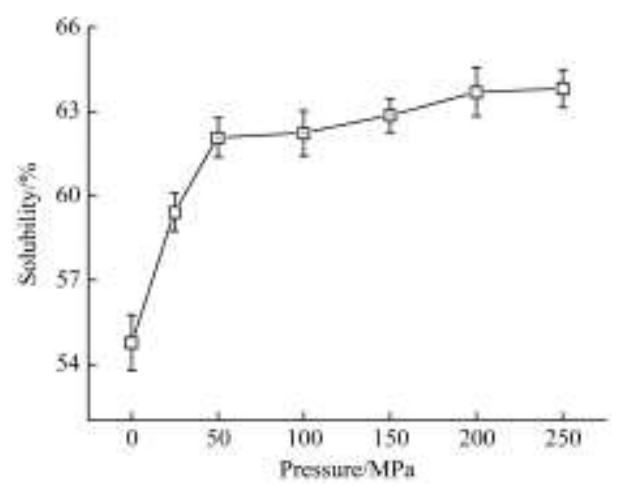

Figure 3 Effects of dynamic UHPH on the aqueous solubility of casein

\subsection{Effects of dynamic UHPH on the foaming properties of casein}

The foaming properties of a protein are its capacity of forming a thin film at the gas-liquid interface and stabilizing the foam, which can be characterized by foaming capacity and foaming stability. The effects of dynamic UHPH on the foaming capacity and foaming stability of casein were shown in Figure 4. With the increasing pressure level, the foam capacity of the casein was firstly increased and then decreased, while the foam stability of the casein was firstly decreased and then increased. As the block copolymers from hydrophilic and hydrophobic amino acids, casein possesses a strong surface activity, and was easy to create foams in the process of mixing. The main factors that affect the foam capacity of casein include solubility, molecular chain flexibility, hydrophobicity, protein concentration, foam generation methods, and so on. For its foaming stability, it mainly depends on the 
rheological properties of the protein, such as hydration of the protein in the adsorption film, protein concentration and thickness of the film ${ }^{[27,28]}$. It was reported that the dynamic UHPH could improve the solubility and molecular flexibility of proteins, and reduce their interfacial tension. Therefore, casein molecules were more likely to be unfolded and adsorbed at the gas-water interface and to form a hard film at the gas-water interface, thus improving the foaming properties of casein ${ }^{[29]}$. However, when the pressure level further increased, the dynamic UHPH destroyed the equilibrium between hydrophobic/hydrophilic groups. Most of the hydrophobic structures of the casein were exposed, which was not favorable for the equilibrium of the protein film in the gas-water interface and the formation of foams ${ }^{[30]}$. Result from this study coincided with these previous reports.

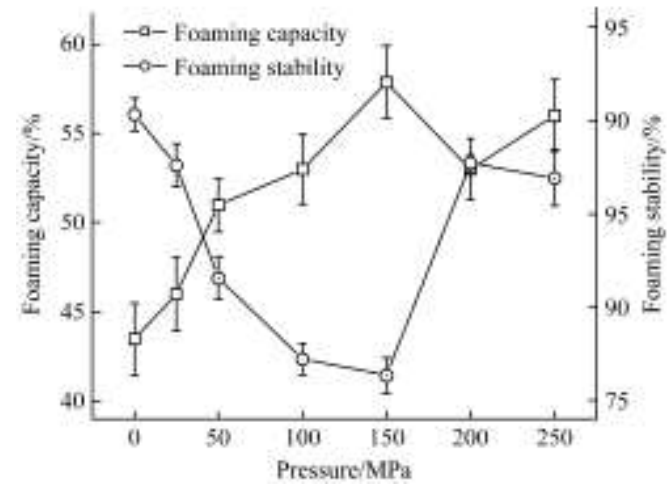

Figure 4 Effects of dynamic UHPH on the foaming properties and foaming stability of casein

\subsection{Effects of dynamic UHPH on the emulsifying properties of casein}

The emulsifying activity of proteins is their capacity to form the emulsions by reducing the interfacial tension of the oil-water surface. The effects of dynamic UHPH on the emulsifying capability (EA) and the emulsifying stability (ES) of casein were exhibited in Figure 5. With the increasing pressure level, the emulsifying capability of casein exhibited a downward trend after the initial increase and showed the maximum value at $100 \mathrm{MPa}$, while the emulsifying stability showed a downward trend after the initial increase. The enhancement in the emulsifying capability of casein might be due to the exposure of the hydrophobic and hydrophilic groups of the casein molecules during the homogenization process. Additionally, the dynamic UHPH improved the solubility and surface hydrophobicity of casein, thereby increased the emulsifying properties. When the pressure further increased, the unfolded casein molecules formed the polymers again by the hydrogen bonds, the disulfide bond and other forces. The molecular chain flexibility decreased so that protein and oil droplets were difficult to combine. The thermal effect of high-pressure homogenization became more significant, and the mechanical action and thermal effect were mutually affected, causing a certain degree of protein denaturation, a decrease in the surface hydrophobicity of protein and a decrease in the emulsifying capability of casein. Figure 6 exhibited the effects of dynamic UHPH on the particle size of the casein emulsion. The mean particle size of the emulsion gradually decreased with the increase of pressure, and tended to reach equilibrium. Cheng et al. also found that the dynamic ultra-high pressure treatment could decrease the particle size of the emulsion $^{[31]}$. Results from this study suggested that when the pressure was higher than $50 \mathrm{MPa}$, the dispersion and aggregation of the emulsion reached a relative equilibrium, and the mean particle size of the emulsion tended to be stable.

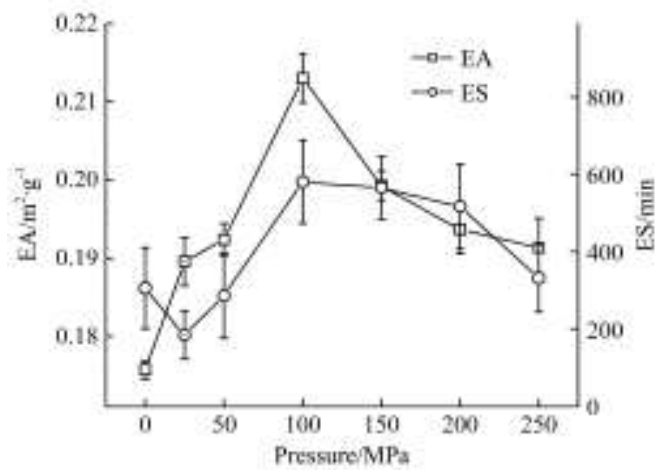

Figure 5 Effects of dynamic UHPH on the emulsifying capability (EA) and emulsifying stability (ES) of casein

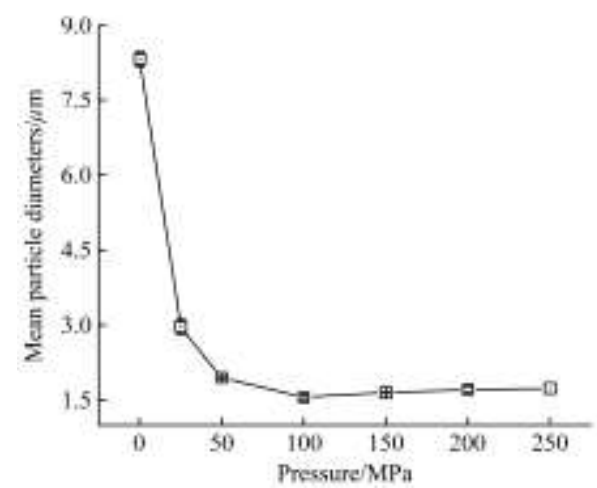

Figure 6 Effects of dynamic UHPH on the average particle size of casein emulsion

3.6 Effects of dynamic UHPH on the content of the sulfhydryl group and the disulfide bonds

The mercapto groups and the disulfide bonds are important functional groups of proteins, which belong to the weak secondary bonds that maintain the three-dimensional structure of protein. Changes in their contents can reflect the degree of protein denaturation and play an important role in the use of protein functional properties. Some processing methods (such as high pressure, heating, and others) will lead to the changes in the contents of the sulfhydryl group and the disulfide bond, causing protein denaturation. Li et al. ${ }^{[32]}$ and Yang et al. ${ }^{[33]}$ reported that the increased content of the sulfhydryl group in high-pressure treated soybean protein suggested a change in the protein conformation. Figure 7 shows that with the increasing pressure level, the content of the sulfhydryl group in the protein first increased to a peak value and then decreased, while the disulfide bond content decreased to a low value first and then increased. It was referred that under dynamic UHPH, the casein molecules underwent the following changes: First, the structure of casein was unfolded and became loose, allowing the internal disulfide bonds to be exposed to the molecular surface. Due to some strong local molecular activities, some disulfide bonds were broken and reduced to form sulfhydryl groups. Secondly, some sulfhydryl groups that were exposed on the surface of molecules combined with the oxygen in the air to form disulfide bonds. Furthermore, since the interface newly formed by protein particles was thermodynamically unstable, the sulfhydryl groups were folded and embedded inside the molecules. The results suggested that the breakage of the disulfide bond was dominant in the range of $0.1-150 \mathrm{MPa}$, so the content of the sulfhydryl group was gradually increased, and the content of disulfide bond was reduced 
accordingly. At the pressures of 150-250 MPa, the oxidation and embedment of the sulfhydryl group were dominant, so the content of the sulfhydryl group and the disulfide bonds decreased and increased, respectively.

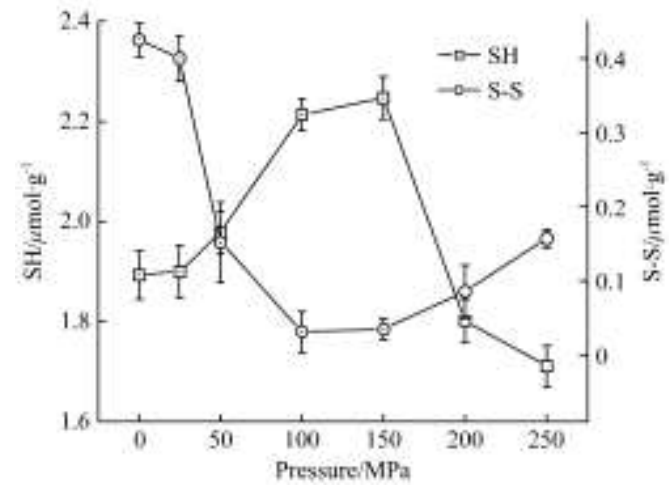

Figure 7 Effects of dynamic UHPH on the content of the sulfhydryl group and the disulfide bond in casein

\subsection{Effects of dynamic UHPH on the surface hydrophobicity of casein}

Hydrophobic interaction is the main force affecting the tertiary structure of proteins, has a significant effect on the functional properties of proteins such as solubility, emulsifying property and foaming property. The effects of dynamic UHPH on the surface hydrophobicity of casein were shown in Figure 8. The surface hydrophobicity of casein could be significantly increased by the treatment at $100 \mathrm{MPa}$. In the natural state, most of the non-polar amino acid residues are located in the intramolecular regions to form a stable hydrophobic core, while the polar amino acids are distributed on the protein molecular surface to maintain the interactions with water molecules, thus ensuring the stability of the hydrophilic environment ${ }^{[34]}$. Figure 8 indicated that the surface hydrophobicity could be enhanced after treated by dynamic UHPH.

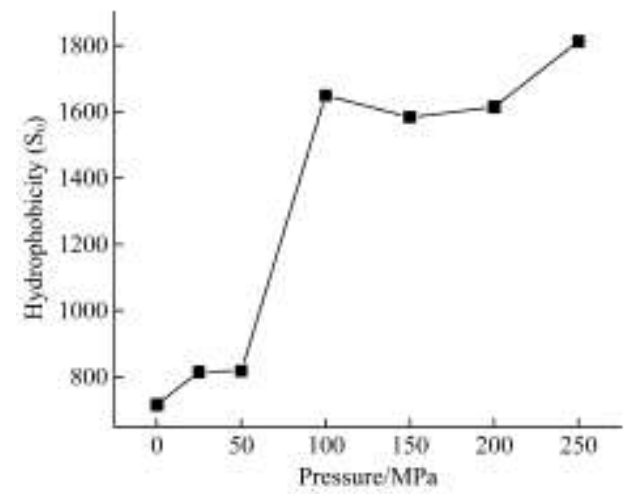

Figure 8 Effects of dynamic UHPH on surface hydrophobicity of casein

\subsection{Effects of dynamic UHPH on the secondary structure of casein}

The effects of dynamic UHPH on the secondary structure of casein were shown in Table 1 . The conformation of casein changed in the pressure-dependent manner. The contents of $\alpha$-helix and $\beta$-Sheet structures gradually decreased and increased, respectively. The hydrogen bonds between carbonyl groups and amino groups in proteins account for maintaining the $\alpha$-helical structure $^{[35]}$, which was sensitive to the dynamic UHPH treatment. $\beta$-sheet is a typical structure of conversion from globule to fibers and probably accompanies the occurrence of protein denaturation.
It could be concluded that the casein structure was stretched and rearranged, and its flexibility was enhanced, which caused the change of the functional properties of casein.

Table 1 Effects of dynamic UHPH on the secondary structure

\begin{tabular}{ccccc}
\multicolumn{5}{c}{ of casein } \\
\hline Sample & $\alpha$-Helix & $\beta$-Sheet & $\beta$-Turn & Random coils \\
\hline $0 \mathrm{MPa}$ & $11.30 \%$ & $26.2 \%$ & $27.30 \%$ & $37.80 \%$ \\
$25 \mathrm{MPa}$ & $10.10 \%$ & $28 \%$ & $27.60 \%$ & $38.30 \%$ \\
$50 \mathrm{MPa}$ & $9.80 \%$ & $29.1 \%$ & $27.20 \%$ & $38.30 \%$ \\
$100 \mathrm{MPa}$ & $10.10 \%$ & $28.1 \%$ & $27.30 \%$ & $38.10 \%$ \\
$150 \mathrm{MPa}$ & $9.60 \%$ & $29.3 \%$ & $27.30 \%$ & $38.30 \%$ \\
$200 \mathrm{MPa}$ & $9.30 \%$ & $30.5 \%$ & $26.60 \%$ & $38.20 \%$ \\
$250 \mathrm{MPa}$ & $8.30 \%$ & $34.7 \%$ & $25.20 \%$ & $38.10 \%$ \\
\hline
\end{tabular}

\section{Conclusions}

In this study, the dynamic UHPH treatment affecting the functional properties of casein was investigated. It was found that the treatment at $150 \mathrm{MPa}$ improved the solubility, foaming properties and emulsifying properties of casein. These functional improvements could be attributed to casein structural changes, since the dynamic UHPH treatment changed the secondary structure, promoted the interchange reaction between disulfide bond and sulfhydryl group, and increased the surface hydrophobicity. The obtained results could broaden the application of casein and provide ideas for the non-thermal processes of proteins.

\section{Acknowledgements}

This research was supported by the National Natural Science Foundation of China (No. 31571912) and the Major Science and Technology Project in Henan (No. 161100110600).

\section{[References]}

[1] Marinova K G, Basheva E S, Nenova B, Temelska M, Mirarefi A Y, Campbell B, et al. Physico-chemical factors controlling the foamability and foam stability of milk proteins: Sodium caseinate and whey protein concentrates. Food Hydrocolloids, 2009; 23(7): 1864-876.

[2] Thorn D C, Ecroyd H, Carver J A. The two-faced nature of milk casein proteins: amyloid fibril formation and chaperone-like activity. Australian Journal of Dairy Technology, 2009; 64(1): 34-34.

[3] Zhou Y, Yi X, Wang J, Yang Q, Wang S. Optimization of the ultrasonic-microwave assisted enzymatic hydrolysis of freshwater mussel meat. Int J Agric \& Biol Eng, 2018; 11(5): 236-242.

[4] Korhonen H J. Bioactive milk proteins and peptides: from science to functional applications. Australian Journal of Dairy Technology, 2009; 64(1): 34-40.

[5] Post A E, Ebert M, Hinrichs J. $\beta$-casein as a bioactive precursor-processing for purification. Australian Journal of Dairy Technology, 2009; 64(1): 84-88.

[6] Wang T T, Guo Z W, Liu Z P, Feng Q Y, Wang X L, Tian Q, et al. The aggregation behavior and interactions of yak milk protein under thermal treatment. Journal of Dairy Science, 2016; 99(8): 6137-6143.

[7] Huang Z, Cao Y, Xu D, Wang C, Zhang D. Effect of ultrasound on the diffusion properties of casein entrapped in alginate-chitosan gel. Ultrasonics Sonochemistry, 2015; 26: 149-156.

[8] Rahimi M, Ghaffari S M, Salami M, Mousavy S J, Niasari-Naslaji A, Jahanbani R, et al. ACE-inhibitory and radical scavenging activities of bioactive peptides obtained from camel milk casein hydrolysis with proteinase K. Dairy Science \& Technology, 2016; 96(4): 489-499.

[9] Chandrapala J, Martin G J, Kentish S E, Ashokkumar M. Dissolution and reconstitution of casein micelle containing dairy powders by high shear using ultrasonic and physical methods. Ultrasonics Sonochemistry, 2014; 21(5): 1658-1665. 
[10] Francesca P, Rosalba L. Applications of high and ultra high pressure homogenization for food safety. Frontiers in Microbiology, 2016, 7: 1132 .

[11] Zamora A, Guamis B. Opportunities for ultra-high-pressure homogenisation (UHPH) for the food industry. Food Engineering Reviews, 2015; 7(2): 130-142.

[12] Sorensen H, Mortensen K, Sorland G H, Larsen F H, Paulsson M, Ipsen R. Dynamic ultra-high pressure homogenisation of milk casein concentrates: Influence of casein content. Innovative Food Science \& Emerging Technologies, 2014; 26: 143-152.

[13] Zhang X, Haque $\mathrm{Z} Z \mathrm{Z}$. Generation and stabilization of whey-based monodisperse nano emulsions using ultra-high-pressure homogenization and small amphipathic co-emulsifier combinations. Journal of Agricultural and Food Chemistry, 2015; 63(45): 10070-10077.

[14] Ferragut V, Cruz N S, Trujillo A, Guamis B, Capellas M. Physical characteristics during storage of soy yogurt made from ultra-high pressure homogenized soymilk. Journal of Food Engineering, 2009; 92(1): 63-69.

[15] Sorensen H, Mortensen K, Sorland G H, Larsen F H, Paulsson M, Ipsen R. Dynamic ultra-high pressure homogenisation of whey protein-depleted milk concentrate. International Dairy Journal, 2015; 46: 12-21.

[16] Liu X, Yu M. Effects of paraffin emulsion on the structure and properties of soy protein films. Journal of Dispersion Science and Technology, 2016 37(9): 1252-1258.

[17] Le T T, Bhandari B, Holland J W, Deeth H C. Maillard reaction and protein cross-linking in relation to the solubility of milk powders. Journal of Agricultural and Food Chemistry, 2011; 59(23): 12473-12479.

[18] Yang, S Q, He D J, Ning J F. Predicting wheat kernels' protein content by near infrared hyperspectral imaging. Int J Agric \& Biol Eng, 2016; 9(2): $163-163$.

[19] Yin S W, Tang C H, Cao JS, Hu E K, Wen Q B, Yang X Q. Effects of limited enzymatic hydrolysis with trypsin on the functional properties of hemp (Cannabis sativa L.) protein isolate. Food Chemistry, 2008; 106(3): 1004-1013.

[20] Liu L L, Wang H, Ren G Y, Duan X, Li D, Yin G J. Effects of freeze-drying and spray drying processes on functional properties of phosphorylation of egg white protein. Int J Agric \& Biol Eng, 2015; 8(4): 116-123.

[21] Manfo F P, Chao W F, Moundipa P F, Pugeat M, Wang P S. Effects of maneb on testosterone release in male rats. Drug and Chemical Toxicology, 2011; 34(2): 120-128.

[22] Zhao Q, Selomulya C, Xiong H, Chen X D, Ruan X, Wang S, et al. Comparison of functional and structural properties of native and industrial process-modified proteins from long-grain Indica rice. Journal of Cereal Science, 2012; 56(3): 568-575.

[23] Jambrak A R, Mason T J, Lelas V, Herceg Z, Herceg I L. Effect of ultrasound treatment on solubility and foaming properties of whey protein suspensions. Journal of Food Engineering, 2008; 86(2): 281-287.

[24] Jafari S M, He Y, Bhandari B. Production of sub-micron emulsions by ultrasound and microfluidization techniques. Journal of Food Engineering, 2007; 82(4): 478-488.

[25] Chandi G K, Sogi D S. Functional properties of rice bran protein concentrates. Journal of Food Engineering, 2007; 79(2): 592-597.

[26] Shanmugam A, Chandrapala J, Ashokkumar M. The effect of ultrasound on the physical and functional properties of skim milk. Innovative Food Science \& Emerging Technologies, 2012; 16: 251-258.

[27] Le T T, Bhandari B, Holland J W, Deeth H C. Maillard reaction and protein cross-linking in relation to the solubility of milk powders. Journal of Agricultural and Food Chemistry, 2011; 59(23): 12473-12479.

[28] Dombrowski J, Dechau J, Kulozik U. Multiscale approach to characterize bulk, surface and foaming behavior of casein micelles as a function of alkalinisation. Food Hydrocolloids, 2016; 57: 92-102.

[29] Bolontrade A J, Scilingo A A, Anon M C. Amaranth proteins foaming properties: Film rheology and foam stability-Part 2. Colloids and Surfaces B: Biointerfaces, 2016; 141: 643-650.

[30] Sharma P, Oey I, Everett D W. Thermal properties of milk fat, xanthine oxidase, caseins and whey proteins in pulsed electric field-treated bovine whole milk. Food chemistry, 2016; 207: 34-42.

[31] Qian C, McClements D J. Formation of nanoemulsions stabilized by model food-grade emulsifiers using high-pressure homogenization: factors affecting particle size. Food Hydrocolloids, 2011; 25(5): 1000-1008.

[32] Li H, Zhu K, Zhou H, Peng W. Effects of high hydrostatic pressure treatment on allergenicity and structural properties of soybean protein isolate for infant formula. Food Chemistry, 2012; 132(2): 808-814.

[33] Yang H, Yang A, Gao J, Chen H. Characterization of physicochemical properties and IgE-binding of soybean proteins derived from the HHP-treated seeds. Journal of Food Science, 2014; 79(11): C2157-2163.

[34] Riebroy S, Benjakul S, Visessanguan W, Erikson U, Rustad T. Acid-induced gelation of natural actomyosin from Atlantic cod (Gadusmorhua) and burbot (Lotalota). Food Hydrocolloids, 2009; 23(1): 26-39.

[35] Chapleau N J, de Lamballerie-Anton M I. Changes in myofibrillar proteins interactions and rheological properties induced by high-pressure processing. European Food Research and Technology, 2003; 216(6): $470-476$. 